\title{
The saga of the peer review process: author's perspective
}

\author{
Mayank Agrawal ${ }^{1}$ and Suhani Suhani ${ }^{2 *}$
}

\begin{abstract}
Peer review system is the cornerstone of scientific publishing. The indented process is not as tedious as it has become, mainly due to the time delay, unavailability of expert reviewers, and the callous attitude of some. While there have been articles explaining the whole process and expressing the editor's viewpoints on the peer review system, we wish to present the author's perspective on this system.
\end{abstract}

Scientific publishing depends largely on the peer review system. The peer review system is key to maintain the quality of scientific publishing [1]. The peer review system was introduced in scientific journals more than 300 years ago. "The Philosophical Transactions of Royal Society" has been considered the first journal to formalise this system [2].

Though we know its pitfalls, peer review continues to be the most trusted buddy. It is often blinded, making the review process unbiased and fair to the authors if followed in the true spirit [3]. The indented process is not as tedious as it has become, mainly due to the time delay, unavailability of expert reviewers, and the callous attitude of some. While there have been articles explaining the whole process and expressing the editor's viewpoints on the peer review system, we wish to present the author's perspective on this system $[1,4]$.

The peer review process helps to improve the quality of manuscripts that are deemed suitable for publication. It filters out the low-quality manuscripts and prevents them from reaching the scientific community. The major advantage of a peer review process is that peer reviewed articles provide a trusted scientific communication form [4]. The peer review process is a voluntary unpaid job and works on the principle of trust at each stage.

\footnotetext{
*Correspondence: drsuhani@gmail.com

${ }^{2}$ Department of Surgical Disciplines, All India Institute of Medical

Sciences, New Delhi 110029, India

Full list of author information is available at the end of the article
}

Firstly, it is assumed the reviewers to be competent and well versed with the subject. Sadly, most journals do not routinely ask for the curriculum vitae to confirm if the reviewer has the requisite expertise on the subject they are willing to review. Many a times, the "areas of interest" section on the manuscript submission site gathers the information about the reviewer(s). The reviewer may have made the account some years ago, and the interest could have changed. This leads to substandard quality of reviewers (for a particular subject) who review manuscripts that are not in line with their interest. To ensure that the manuscripts are reviewed by the reviewers with desired expertise, the reviewer's curriculum vitae, especially the younger reviewers, should be reviewed periodically such as on an annual basis. Also, a checklist gathering brief information about the reviewer (including the area of expertise) could be made mandatory prior to the reviewer accepting or rejecting the invitation to peer review a manuscript. These will help to strengthen the journal's database on reviewers.

Secondly, it is expected by the authors that the reviewer will offer an unbiased opinion and not have any conflict of interest concerning the manuscript in question. It is now not uncommon to see reviewers "demanding authors to cite certain articles" in the manuscript. Very often, the authors do not consider them in line with the content of the manuscript. But, the sad reality is that most of them succumb to the reviewer's demand in the hope that their work shall get accepted. 
The third distressing part which the authors face is the time delay in the peer review process. Usually, the review cycle is $2-3$ weeks, but it is not uncommon to see the reviewers reviewing the articles weeks/months after being assigned the manuscript. Sometimes, the manuscripts are rejected 6-12 months after the submission. This is extremely unfair and unjust for the authors as precious time is lost in due process.

Also, it is often seen that one of the reviewers enlists pages of queries, with most of them being either irrelevant to the subject in question or addressing the points which have already been mentioned in the manuscript. As this reviewer is often quoted as the 'reviewer 2' in the author's emails, the '\#reviewer2' has often been used on social media platforms by the authors to express their unhappiness towards this scenario. It is disappointing and purposeless to the author(s). To top it all, after doing the necessary rounds of corrections with each cycle taking months, the reviewer sometimes disregards their previous comments and amendments done for them and goes to reject the manuscript-this time multiplying the misery of the authors! We would suggest that there should be a way to assess the quality of review based on the time taken to review and the quality of comment(s) made by the reviewer. This will allow re-categorisation and grading of reviewers that will be accessible to the editors, eventually making the review process more gratifying for the authors.

Another problem which hits the authors hard is the editor's decision sometimes to send the manuscript to an entirely new set of reviewers during the second cycle of peer review process. These new reviewers have their own set of queries/comments. The author has no choice but to revise the manuscript yet again, which is sometimes diagonally opposite to the revision done after receiving the comments of the first set of reviewers. This is timeconsuming, and it can be entirely avoided if the revised manuscript is sent back to the initial set of reviewers.

At times, the manuscript is rejected by the editor(s) before the review process starts. Choosing the right journal for publishing one's manuscript is important. If the manuscript subject is out of the 'scope of the journal', the editor(s) may outrightly reject the manuscript. Hence one needs to read 'scope of the journal' before submitting the manuscript. Other common reasons for rejection at the editor level are the unimportant topic, lack of originality or poorly written manuscripts, and unacceptable ethical/integrity issues. We appreciate this lead taken by the editors as it saves important time for the authors and prevents burdening the reviewers with manuscripts which would be ultimately deemed unfit by the editors.

We end our saga by acknowledging the hard work of reviewers around the world. Reviewers are backbone of scientific research. We want to appeal to the reviewers to take on the peer review process as they would expect a peer to review their manuscript. Also, we feel that the editors could take a step in between and consider making decisions for the manuscripts after minor revisions have been done to help complete the review faster.

\section{Acknowledgements \\ Not applicable. \\ Authors' contributions \\ MA and SS have made substantial contributions to the conception and design of this manuscript. Both were involved in the data acquisition and jointly drafted the work and revised it as per the need. Both were involved in the manuscript drafting, editing and review. Manuscript was finally approved by both the contributors. MA and SS have agreed to be accountable for the manuscript submitted. Both authors read and approved the final manuscript. \\ Funding \\ This research received no specific grant from any funding agency in the pub- lic, commercial, or not-for-profit sectors.}

\section{Availability of data and materials \\ Data sharing is not applicable to this article as no datasets were generated or analysed during the current study.}

\section{Ethics approval and consent to participate}

Not applicable.

\section{Consent for publication}

Not applicable.

\section{Competing interests}

The authors declare that they have no competing interests.

\section{Author details}

${ }^{1}$ Department of Urology, Grant Government Medical College and Sir JJ Hospital, Mumbai, India. ${ }^{2}$ Department of Surgical Disciplines, All India Institute of Medical Sciences, New Delhi 110029, India.

Received: 9 November 2020 Accepted: 12 February 2021

Published online: 25 February 2021

\section{References \\ 1. Tullu MS, Karande S (2018) Success in publishing: selecting an appropri- ate journal and braving the peer-review process. J Postgrad Med 64:1-4 \\ 2. Csiszar A (2016) Peer review: troubled from the start. Nature 532:306-308 \\ 3. Tumin D, Tobias JD (2019) The peer review process. Saudi J Anaesth 13:S52-S58 \\ 4. Kelly J, Sadeghieh T, Adeli K (2014) Peer review in scientific publications: benefits, critiques, \& a survival guide. EJIFCC 25:227-243}

\section{Publisher's Note}

Springer Nature remains neutral with regard to jurisdictional claims in published maps and institutional affiliations. 